\title{
The need for a national policy for the management of inherited metabolic disease
}

\author{
D. N. RAINE
}

From the Department of Clinical Chemistry, The Children's Hospital, Birmingham

Clinical education is based on the apprenticeship system and depends upon the student having personal experience of most of the disorders that he is likely, in the future, to have to deal with. For more unusual or difficult problems, a system of specialist consultants exists and some of these are inclined to specialize even further by seeking out groups of related, but even more unusual, disorders such as muscular dystrophy or childhood coeliac disease, and to devise systems of care that would otherwise remain untried and unavailable. For disorders even less common than muscular dystrophy, such as the rare metabolic diseases, the undergraduate educational system breaks down, and unless special attention is drawn to one of these, as with phenylketonuria (because it was one of the first chronic forms of mental subnormality to be treatable), or with galactosaemia (because it often presents with recognizable clinical features and again can be treated) it is likely to pass unrecognized by many medical consultants and to remain unknown to most family doctors (the educational system does not allow it to be otherwise). There are already more than 100 of these rare metabolic disorders inherited by recessive or sex-linked mechanisms for which the precise enzyme deficiency is known: there are altogether 950 diseases inherited by similar mechanisms and may soon prove to be metabolic in origin (McKusick, 1971). These diseases collectively constitute a significant part of clinical medicine which the present structure of health care does not allow of satisfactory management.

The present discussion is concerned with the size and nature of this problem and the possible ways in which it can be resolved.

\section{The Size of the Problem}

Many of the inherited metabolic diseases are associated with mental handicap of an order that requires long-term institutional care. Others, which at present are fatal in early life, while they are not an economic burden on the community, are so temptingly near to being treatable that there is a strong human desire to improve the means to do this. Unfortunately, good estimates of the incidence of these diseases are available in very few instances and so the real size of the problem must be approached indirectly. Two approaches are possible: one from the known incidence of known diseases provides a minimum figure; the other, from an estimate of the proportion of paediatric admissions to hospital, paediatric deaths, and patients who are mentally subnormal and have an underlying metabolic disease also provides a useful figure. Estimates by both of these approaches will be made.

\section{INCIDENCE OF SOME SPECIFIC METABOLIC} DISORDERS

Surveys of these relatively rare conditions must cover hundreds of thousands of subjects before the number of affected patients is large enough to give a statistically significant assessment of their incidence. The number of satisfactory surveys is regrettably few: the following, however, provide usable data and are summarized in table I.

\section{World Health Organization (1972)}

The source of these data is not stated but there port is prepared by an experienced group of workers in the field of inherited metabolic disease and must have derived from large population screening programmes.

\section{Council of Europe Public Health Committee (1973)}

These data derive from centres screening for various combinations of inherited metabolic diseases in the neonatal population in eight countries. The cases discovered and the size of populations screened were: for phenylketonuria, 668 in 5252000 (a rate of $12.7 \times 10^{-5}$ ); for histidinaemia 18 in $214703\left(8.4 \times 10^{-5}\right)$; and for galactosaemia 21 in $725857\left(2.9 \times 10^{-5}\right)$.

\section{Other sources}

A careful estimate of the incidence of the adrenogenital syndrome (without considering separately the several different enzyme deficiencies leading to 


\begin{tabular}{|c|c|c|c|c|c|}
\hline Metabolic Disease & $\mathrm{WHO}^{1}$ & Council of Europe ${ }^{2}$ & Frequency Used & $\begin{array}{l}\text { New Cases in } U K \\
\text { per Year }\end{array}$ & $\begin{array}{l}\text { Estimated Life } \\
\text { Expectancy }(y)\end{array}$ \\
\hline Phenylketonuria & $7 \cdot 0$ & $12 \cdot 7$ & 10 & 100 & $50+$ \\
\hline Hyperphenylalaninaemia & $3 \cdot 0$ & - & - & - & - \\
\hline Histidinaemia & $6 \cdot 0$ & $8 \cdot 4$ & 7 & 70 & $50+$ \\
\hline Galactosaemia & $3 \cdot 0$ & 2.9 & 3 & 30 & $20+$ \\
\hline Homocystinuria & 6.0 & - & 6 & 60 & $20+$ \\
\hline Cystinuria & $7 \cdot 0$ & - & 7 & 70 & $50+$ \\
\hline Maple syrup urine disease & 0.3 & - & $0 \cdot 3$ & 3 & 5 \\
\hline Argininosuccinicaciduria & 0.5 & - & 0.5 & 5 & $20+$ \\
\hline Adrenogenital syndrome & - & - & $14 \cdot 3^{3}$ & 143 & $20+$ \\
\hline Cystic fibrosis & $50 \cdot 0$ & - & $50 \cdot 0$ & 500 & $20+$ \\
\hline Prolinaemia & - & - & $10 \cdot 8^{6}$ & - & $50+$ \\
\hline
\end{tabular}

Table I Frequency (per 100000 births) and rate of occurence of new cases of specific inherited metabolic diseases 'World Health Organization (1972); ' ${ }^{2}$ Council of Europe Public Health Committee (1973); 'Hubble (1966); 'Raine, Cooke, Andrews, and Mahon (1972)

this) was made by Hubble (1966). Data for prolinaemia type 1 were collected for the Council of Europe survey but not published. The incidence from the survey by Raine, Cooke, Andrews, and Mahon (1972) is included in table I and represents six cases in 55715 babies tested. However, there is an increasing feeling that prolinaemia type 1 may be a biochemical abnormality that is only coincidentally associated with disease symptoms and so this condition has not been included in any of the calculations in the present paper.

Table I also contains the number of new cases born in the United Kingdom each year assuming 1 million births annually (in 1970 there were 902500 live births).

The significance of these several diseases, of course, is different. Those so serious as to lead to death in infancy can be largely discounted; others allow the patient to survive childhood with treatment and others do not significantly shorten life. Some of these patients, when well treated, are associated with a normal productive life, but others may need institutional care for many years. It is impossible to be either accurate or even very dogmatic about these factors for a particular disease, but in an attempt to consider one of them, a somewhat subjective assessment of life expectancy is also included in table I. The life span given is neither the mean nor the maximum age, and the age reached by many patients has been reduced when there is a tendency for death to occur in childhood even though some patients may survive long after this.

Calculating the number of new cases of inherited metabolic disease each year in the United Kingdom on the basis of these 10 diseases the number will be about 985 (say 1000), and most of these will require substantial medical or institutional care for several years if treated satisfactorily. However, if treated inadequately or allowed to remain undiagnosed, many will require treatment or institutional care for much longer, although some would of course die.

INCIDENCE BASED ON PAEDIATRIC DEATHS

Two careful studies have been made of the proportion of deaths in children's hospitals that can be attributed to genetic causes. The first (Carter, 1956), based on 200 deaths, gave a figure of $12 \%$, but did not differentiate single gene defects from chromosome disorders. The second and larger study of 1041 deaths (Roberts, Chavez, and Court, 1970) agreed with the earlier that the proportion due to genetic causes was $11 \%$. Of the $2.5 \%$ that were chromosomal in origin most were cases of Down's syndrome, but the remaining $8.5 \%$ were attributable to recessive or sex-linked disorders, the form of inheritence most likely to be associated with disease of metabolic origin. Indeed 53 of the 88 recessive and sex-linked disorders were certainly metabolic, the precise cause being known.

The number of paediatric deaths in England and Wales can be ascertained from the Registrar General's Statistical Review for 1971 (Office of Population Censuses and Surveys, 1973) as follows: Table 4 of the report shows that there were, in 1971, for children aged 1-14 years, 1.36 deaths per 1000 living children. Table 1 gives 10894900 as the population aged 1-14, thus the deaths in this age group were 14800 . For children under 1 year, those who died under 1 month are excluded from the present calculations. The number of deaths of children aged 1 month to 1 year was 4607 (table 13). The total childhood deaths between 1 month and 14 years was, therefore, 19407 , and the number $(8.5 \%$ of the total) due to inherited metabolic diseases is 1650 . The children dying in less than one month are excluded, not because the illness is less likely to be of genetic origin, but because there is little opportunity to diagnose them and institute 
effective treatment. This situation could considerably change in the future, in which case the number of deaths under 1 year used in this calculation should be trebled.

\section{INCIDENCE BASED ON PAEDIATRIC}

\section{ADMISSIONS}

In an attempt to determine the frequency of genetic disease the patients admitted to Montreal Children's Hospital in 1969-70 were classified under a number of headings (WHO, 1972, table 1). Of the total admissions, $4.7 \%$ had a recessive or sex-linked genetic disorder. Thus, if admissions in the UK are comparable, this provides another means of assessing the case load of inherited metabolic disease. In 1972 there were 856670 discharges of children aged 0-14y in England and Wales (taken from the Report on the Hospital In-patient Enquiry, 1972) and 4.7\% of this is 40260 . This should be divided by the average annual discharges for each individual. This figure is not known but is probably between 2 and 5 , giving an annual case load between 8052 and 20130

PREVALENCE OF INHERITED METABOLIC

DISEASE AMONG THE MENTALLY HANDICAPPED Diagnostic precision in the field of mental handicap is increasing so rapidly that early surveys of the aetiological factors are now of little value. However, Berg (1963) found in a survey of 800 consecutive admissions to the Fountain Hospital 22 cases $(2.8 \%)$ of metabolic disease. In the now classical study in Northern Ireland by Carson and Neill (1962), a survey of 2081 mentally retarded individuals yielded, apart from a number of generalized amino acidurias of unknown significance, $62(3.0 \%)$ cases of specific metabolic disease.

In a later survey by Carson (1970) of 5523 mentally retarded subjects and 4126 patients suspected of having an amino acid disorder, 116 patients $(1.2 \%)$ were found to have an inherited metabolic disease and only 11 of these patients were not mentally retarded. This survey will be affected by the fact that nearly half of those screened did not have mental handicap. The ratio of patients with inherited metabolic disease and mental handicap to the number of mentally handicapped children screened, 105 in 5523, gives an incidence of $1.9 \%$.
A survey of children admitted for assessment or long-term care to Queen Mary's Hospital, Carshalton, showed that of 645 children, 21 (3.3\%) had an inherited metabolic disease (Angeli and Kirman, 1971).

It would seem reasonable to assume that $3 \%$ of mental handicap is associated with metabolic diseases that can be recognized by the relatively simple investigations used in most of these surveys and that this is a minimal figure.

\section{INCIDENCE BASED ON PROBABLE}

PROPORTION OF MENTALLY SUBNORMAL PATIENTS WITH INHERITED METABOLIC DISEASE

The annual rate of ascertainment of mental handicap can be derived from surveys in Wessex, Newcastle upon Tyne, and Camberwell (DHSS and WO, 1971, table 1). The number of mildly and severely affected individuals, aged $0-14 y$, in hospital and at home was 73 per 100000 total population. Taking the total population of the UK as 50 million, this gives a total mentally handicapped population of 36500 . The annual rate of ascertainment will be one fifteenth of this, 2433, and the number associated with inherited metabolic disease, at the rate of $3.0 \%$, will be $73 /$ year. This is a surprisingly low figure and probably reflects the fact that the surveys are least effective in ascertaining the mild to moderate degrees of mental handicap in individuals living at home. Generally the handicap associated with metabolic disease is of this order rather than the very severe degree of handicap that requires almost all those affected to be cared for in hospitals for the subnormal.

SUMMARY OF ASSESSMENTS OF THE SIZE OF THE PROBLEM

The number of new cases of inherited metabolic disease derived in these various ways is summarized in table II, and they are all close enough to make them reasonably credible. Although some are for the UK and others for England and Wales, the difference is scarcely significant considering the error involved in the derivation of the figures.

The annual case load cannot be less than 1000

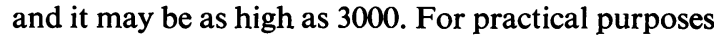

Sum of known diseases of known incidence

$8.5 \%$ Paediatric deaths have a recessive or sex-linked genetic cause

4.7\% Paediatric hospital admissions are due to recessive and sex-linked genetic disease

$3 \%$ Mental subnormality is due to inherited metabolic disease

For comparison

Down's syndrome

Congenital malformations

Table II Annual occurrence of cases of inherited metabolic disease in the United Kingdom (UK) or England and Wales assessed by different methods 
it would be reasonable to assume that at present it is about 2000. It is unlikely that this number will ever be reduced and, as diagnostic skills improve, it can be expected to increase.

\section{Ideal Requirements for Satisfactory Management}

The successful management by family doctors, consultant paediatricians, nurses, social workers, biochemists, obstetricians, and geneticists of patients, their parents, and prospective parents with some genetic risk involves a number of services, all of which must be readily available and properly coordinated. (1) Accurate information must be assembled and made accessible. (2) Diagnostic services, which may be specialized, should be established. (3) Early detection systems, such as screening for phenylketonuria in the neonatal period, should be instituted in appropriate circumstances. (4) The best information on treatment should be accessible to those concerned with newly diagnosed patients. Existing methods should be improved and new ones devised. (5) Methods of heterozygote detection should be improved and made available. (6) Research into prenatal detection of affected fetuses by amniocentesis should continue until a reliable service can be offered, and the proper place of genetic counselling should continue to be explored. (7) The natural history of the rarer and new diseases needs to be studied in order to ascertain the need for, and the most appropriate form of, management of the condition. (8) A coordinating system for both information and the care of individual patients or subjects at risk, on a national or a supraregional basis, should be designed.

These aspects of the total management of inherited metabolic disease are in different states of development. Thus, while some, such as the Guthrie method of screening for phenylketonuria, and limited extensions of this, are developed to the point where they can be regarded as established forms of service, others, such as prenatal detection by amniocentesis, need further research. Other aspects such as the development of new methods of treatment are still entirely in the research phase. As the different aspects are dicussed an indication will be given of their present state of development into those that can usefully provide a service now (S) and those which require further research before their application can be extended beyond a few centres (R).

\section{INFORMATION SYSTEMS}

$S \quad$ Statements of preferred treatment

$S \quad$ Known patients and their clinicians

\section{$S R \quad$ Medical literature screen}

\section{$R \quad$ Rapid retrieval from literature file}

\section{$R \quad$ Statement of desirable studies of disease}

The value of a continuously revised statement of the treatment of a specific disorder is well illustrated by a patient who suffered a lens dislocation in adult life as a consequence of homocystinuria. Here surgical treatment is moderately urgent but there may be time to treat the patient before the operation in order to minimize the risk of thrombosis. The precise dose of pyridoxine to be given, the optimal frequency of monitoring its effect, the need and extent of reducing the dose after the operation, and the requirements for a low-methionine diet should pyridoxine prove ineffective will rarely be known by the ophthalmologist, and to discover this from the literature would involve unacceptable delays. The information can all be given by telephone and on two occasions recently untreated patients have been improved within two days and rendered safe for surgery within eight days.

For less acute situations, after some initial advice has been given by a reference centre, the clinician will be helped if he can speak directly with those currently treating other patients with a particular metabolic disease. A file of patients and their medical advisers, maintained by the reference centre, would facilitate this.

Keeping abreast of newly published work on all of the inherited metabolic diseases is impossible even for the specialist. It has already been suggested (Raine, 1972) that a population equal to that of the United Kingdom will require five reference centres. Each of these should be able to retrieve from that published sufficient information to deal adequately with about 20 diseases. Having retrieved the information it is necessary to devise means of recovering this from the reference file with the minimum of delay and this will require some experimentation before the best system is established.

As part of the further understanding of a disease and its management it is often neccessary to design the care of future patients in a manner that will yield new information. Those treating patients and to whom new ideas occur may wait several years before these can be tested and the reference centre can greatly hasten this process by maintaining statements of desirable new studies. When new cases become available the already planned studies can be proposed and the help of the clinician sought in making them. 
2 DIAGNOSTIC SERVICE

\section{$S \quad$ Reference laboratories}

\section{$S R \quad$ Selection of crucial diagnostic tests \\ $R \quad$ Computer-assisted diagnosis}

One of the most inhibiting factors preventing paediatricians taking a greater interest in inherited metabolic disease is the difficulty in making the appropriate investigations. This is illustrated by the fact that histological examination of a liver biopsy is still occasionally the first step in the investigation of glycogen storage disease.

For the more unusual diseases such as the organic acidaemias there may be only one or two laboratories in the country able to perform the appropriate analyses and while they are often willing to do so for clinicians outside their area they have no commitment to do this, or indeed to maintain the diagnostic facility beyond the term of interest of the individual who initiated it. To overcome this, the Department of Health and Social Security has taken the first steps to establish supraregional reference laboratories, but so far none have been established to cater adequately for the inherited metabolic diseases. Nonetheless, the informal network of interested laboratories has been doing useful service for several years, and will, no doubt, continue to do this within its available resources.

Only if the laboratory or clinician is acquainted with the latest information will he initiate the most discriminating tests for diagnosis. Thankfully, the galactose tolerance test is probably never performed now to diagnose galactosaemia, the assay of galactose-1-phosphate uridyl transferase in erythrocytes being more generally available. However, the clinician may not be aware of the extent to which the assay of specific enzymes in leucocytes can effect the diagnosis of several neuronal lipid storage diseases more effectively than the only alternative he may know, namely, histological examination of a brain biopsy. The selection of the most discriminating diagnostic tests needs to be continuously reviewed, and the reference centre should be able to advise on, and undertake, those most useful.

The concept of computer-assisted diagnosis has already been applied to a number of disease areas, and the inherited metabolic diseases would seem to be amenable to similar treatment. A program for such a system has been written and is currently being examined to discover the extent to which it can reduce the large number of possible diagnoses (many of which will be overlooked during the conventional diagnostic process) given the symptoms and signs of an individual patient with an inherited metabolic disease.

\section{EARLY DETECTION (TOTAL POPULATION SCREENING)}

Guthrie testing (phenylketonuria, histidinaemia, methioninaemia etc)

$S$

Scriver testing (most amino acid disorders)

\section{$S R \quad$ Limited extensions (eg, galactosaemia)}

The concept of total population screening for phenylketonuria in the neonatal period is now well established and its effectiveness, in terms of the results of the very early treatment of affected children, that it allows have been most rewarding. The same principle has been applied to the detection of histidinaemia and methioninaemia (for itself and as an indication of homocystinuria). The technique is capable of still further extension, but only testing for phenylketonuria is at present advised by the Department of Health and Social Security (H.M. (69) 72).

An alternative method of screening the total neonatal population is by plasma chromatography. This technique, which can detect in one procedure several amino acid disorders, is used regularly in the Manchester Regional Hospital Board area and in the City of Birmingham. It is reported to detect 3.5 times as many children as a simple Guthrie test (Raine et al, 1972) but the question of replacing the latter by this test is not a simple one, and this is not the place to discuss the merits or otherwise of the case.

Screening methods suitable for application to the total neonatal population are available for some other diseases, including galactosaemia and, proably in the near future, for cystic fibrosis. However, it is inconceivable that the hundred or so metabolic diseases will be amenable to this form of detection on a total population basis, and any further extensions of this are likely to be limited technically, and will be increasingly difficult to justify in economic terms.

\section{TREATMENT}

S Treatment centres

$S R \quad$ Standardization and improvement of existing methods of treatment

$R \quad$ Development of new methods of treatment 
The Department of Health and Social Security have recommended (H.M. (69) 72) that experience of treating phenylketonuria should be concentrated as much as possible within the limits imposed by the distances that must be travelled by the patients. The same advice must surely be given for all relatively rare diseases if the best results are to be obtained. However, this is not to deprive individual paediatricians or family doctors of the interest and responsibility for their own patients. In practice it is necessary for the treatment centre to have an interested paediatrician and biochemist, and the resources of an expert dietician, and even a social worker. This team determines the treatment, but once it is established it is usually possible for the supervision to be maintained near the patient's home, and biochemical monitoring can be continued by sending samples to the laboratory, the patient visiting the centre at less frequent intervals as long as metabolic control is maintained.

Centres can maintain a good level of control, even when the patient moves to a different part of the country, and there are considerable advantages in standardizing the treatment of a given condition, provided it does not prevent those centres with a special interest and appropriate facilities from making changes that might result in an improved regime.

There has, in the past, been a rather depressed attitude to the treatment of inherited metabolic disease and, apart from dietary restrictions of the type applied to phenylketonuria, it was believed that there was little to offer. This is no longer so, and a number of diseases are found to respond to various vitamins, some of which act as coenzymes for the defective enzyme, but others are effective by less obvious means. Enzyme replacement has been attempted in various forms, and the results of organ transplants (including bone marrow) justify continuing with these experimental approaches. Treatment of prolinaemia and hydroxyprolinaemia is possible (but as yet of unknown advantage) by blocking renal tubular reabsorption (Cooke and Raine, 1973), and the treatment of the several glycogenoses is now based on much more rational grounds. These several approaches have been briefly reviewed by Raine (1972) and more fully by Raine in 1974. The scope for further research into new methods of treatment of these disorders is unlimited.

\section{HETEROZYGOTE DETECTION}

$S R \quad$ Standardization and improvement of existing methods

\section{$R \quad$ Design of new tests}

\section{$\boldsymbol{R} \quad$ Improved methods of reporting}

The assessment of carrier status is often required by the siblings and more distant relatives of an affected patient about the time of their marriage. While many clinicians will arrange such an assessment when requested, it is rarely offered because the conclusion in about one fifth of subjects is uncertain. While the uncertainty can be reduced by increasing the precision of the test, it is probable that it can never be eliminated. This has led to a change in attitude towards the present methods of testing, whether they are based on direct enzyme assay, in which the heterozygotes have half the normal complement of enzyme activity or on a loading test using the normal substrate of the defective enzyme, in which the heterozygote is less tolerant of the load than a homozygous normal subject. The tests have hitherto been required to give a 'yes' or 'no' answer to whether the subject is heterozygous for the disease in question. By changing this strict requirement and, instead, using the result of the test to calculate the probability that the subject is heterozygous, the accuracy of the conclusion is immediately increased and in certain cases, where a family history is known, an indefinite statement can be made more definite (Westwood and Raine 1973, 1974).

The value of heterozygote tests will be further improved if different laboratories will agree on standard conditions for such procedures as the phenylalanine tolerance test.

There is still scope for improving tests of heterozygosity, especially those based on enzyme assay. For example, it is better to relate the measured enzyme activity to that of another enzyme, not affected by the disease and of comparable activity, than to such parameters as cell count, protein content, or haemoglobin. Similarly in leucocytes and fibroblasts the use of phytohaemaglutinin to bring the cells into a common growth phase further narrows the range of activity characterizing the heterozygous and homozygous normal populations.

The role of genetic counselling centres is still debated. Edwards (1972) believes that for the inherited metabolic diseases at least the genetics are so simple that specialist centres should not be required to give advice which could be given by any family doctor. Nonetheless, many lack the confidence to give this simple advice and until they are able to do so the very real needs (Cowie, 1972) of the families at genetic risk should be met-if necessary by specialist counselling centres. 
More studies, such as that by Carter, Roberts, Evans, and Buck (1971), of the effectiveness of such counselling centres will also help to establish their correct place in the management of these disorders.

\section{PRENATAL DETECTION}

\section{$S \boldsymbol{R} \quad$ Counselling \\ $R \quad$ Performance of tests \\ $R \quad$ Design of new tests}

The ability to recognize that a fetus at risk for a genetic disease is, in fact, affected in time to abort it if this is desired, is an exciting prospect in the management of metabolic disease for which there is no prospect of treatment. Unfortunately, some initial successes have been followed by unbridled enthusiasm and the medical literature already contains reports of mistaken diagnoses and unnecessary abortions and more unpublished cases are known. Much careful work remains to be done before a reliable prenatal detection service can be offered and it is important that this is carried out as quickly as possible in a few centres in order to define safe limits for its more widespread application. Here a nationally organized coordinating system would be of the greatest benefit but none exists and the work is likely to proceed for some time on an ad hoc basis.

In this area, too, further research is needed on the emotional, ethical, and medical aspects of this form of genetic counselling (Cowie, 1972).

\section{NATURAL HISTORY}

\section{$R \quad$ Clinico-pathological studies of specific diseases}

\section{$R \quad$ Recognition of non-diseases}

\section{$R \quad$ Optimal age for testing and treating}

While the better known diseases are receiving more organized and rational attention new diseases will emerge and more cases of hitherto rare conditions will be recognized. Only by knowing the pattern of progress in the untreated disease can the proper treatment or, indeed, the need for treatment, be established. Already there is a growing list of 'diseases' in which an inherited biochemical abnormality was wrongly associated with symptoms and pathology. Cystathioninuria in its inherited form is now known to be a benign biochemical abnormality (there are other serious causes of cystathioninuria but these are not inherited) and Joseph's syndrome, in which proline, hydroxyproline, and glycine are excreted in urine in excess, is similarly a benign defect of a renal tubular transport mechanism. By ensuring that healthy relatives of patients are examined for the biochemical abnormality the reference centre can help to reveal further examples of these coincidental associations.

The optimal age of testing for phenylketonuria has been established by the Medical Research Council Working Party on Phenylketonuria (1968) as 6-9 days and the optimal age for treating the condition is as soon as possible, but not later than 3 months. However, this information has been obtained by a costly process and it does not exist with anything like the same precision for any other inherited metabolic disease. Thus, while it is suspected that 6 days is too late to screen for galactosaemia, this may be too soon if all cases of homocystinuria are to be recognized. These are further arguments against the extension of total population screening in the neonatal period, but this same information is required for the management of any patient with an inherited disease in which the risk is known and the diagnosis can be established before irreversible damage has occurred.

\section{COORDINATION}

\section{$S R \quad$ Patient file-computer linked \\ $R \quad$ Gene file-computer linked}

\section{$S R \quad$ Initial ascertainment}

\section{R Quality control}

\section{$R \quad$ Retrieval conditions-confidentiality}

If the concept is accepted of five reference centres in the United Kingdom, each responsible for keeping itself informed on all aspects of about 20 diseases, so that advice can be given in an immediate fashion on the best methods of diagnosis and treatment, and at the same time offer diagnostic facilities, and be linked with treatment centres using standardized methods, and, where necessary, undertaking the appropriate investigations required for genetic counselling of potential heterozygotes and monitoring pregnancies at risk of genetic disease, then it remains to coordinate this activity and ensure that all centres continue to offer the desired level of service.

Such coordination will be at the national level and details of its structure are open to variation and experiment. It is anticipated that it will require a comprehensive file of affected patients, with or without the aid of a computer. If heterozygote detection develops to the extent some anticipate, a 
computer-linked file of abnormal genes might also be envisaged, but this will require careful consideration of the conditions for entry into, and retrieval from, the file. The problems of legitimacy and of confidentiality are already being examined by those concerned with computer-linked files of patients.

Testing laboratories now take for granted that their performance will be improved by being subject to a quality control programme and this too should be organized from a national centre.

Finally a system for the initial ascertainment of affected individuals, easy enough for most clinicians to be willing to use, should be devised, and a model for this has already been established by the MRC Phenylketonuria Working Parties, and the MRC/ DHSS Phenylketonuria Register in Liverpool.

\section{Discussion}

Much of the organizational structure that has been outlined is relevant to the management of many medical conditions that are already being dealt with satisfactorily. The reason for a special case for inherited metabolic disease has already been accepted in Canada where an informal group of investigators and interested parties has formed 'The Committee for the Improvement of Hereditary Disease Management'. Their objectives are stated at the end of a substantial publication aimed at providing a guide to investigators of inherited metabolic disease (Scriver, Clow, and Lamm, 1973).

In Britain, responsibility, including finance, for service aspects of health care lies with the Department of Health and Social Security, and is administered via the National Health Service. Research into medical developments, however, is largely undertaken by the Medical Research Council and, hitherto, except for minor departures from these two positions, it has been difficult to support satisfactorily developments of what is essentially a service when the research still needed is only relevant if it is agreed that the service can, and should, be developed. Such situations appear to be provided for by the recommendations of Lord Rothschild (Rothschild, 1971) but more controversial issues of that report have obscured the need for such customercontractor-orientated research.

However, regardless of finance, if the need to establish a system of care for inherited metabolic disease could be accepted, the formal coordination of those services that already exist would immediately result in an improvement throughout the country, and a structure would then have been provided within which further developments could take place at whatever rate the national economy will allow.
References

Angeli, E., and Kirman, B. H. (1971). Genetic counselling of the family of the mentally retarded child. In Proceedings of the Second Congress of the International Association for the Scientific Study of Mental Deficiency, pp. 692-696. Policy Medical Publishers, Warsaw.

Berg, J. M. (1963). Causal factors in severe mental retardation. In Proceedings of the 2nd International Congress on Mental Retardation, Vienna, 1961, Part 1, pp. 170-173. Karger, Basle. (Cited by Crome, L., and Stern, J.) (1972). Pathology of Mental Retardation, 2nd ed., p. 8. Churchill Livingstone, Edinburgh. and London.

Carson, N.'A. J. (1970). Disorders of amino acid metabolism: results of screening programmes in Northern Ireland. In Proceedings of the 7th International Congress of Clinical Chemistry, Geneval Evian, 1969, edited by M. Roth, Vol. 3, Hormones, Lipids and Miscellaneous, pp. 320-329. Karger, Basle.

Carson, N. A. J., and Neill, D. W. (1962). Metabolic abnormalities detected in a survey of mentally backward individuals in Northern Ireland. Arch. Dis. Childh., 37, 505-513.

Carter, C. O. (1956), Changing patterns in the causes of death at The Hospital for Sick Children. Grt Ormond St. J., 11, 65-68.

Carter, C. O., Roberts, J. A. F., Evans, K. A., and Buck, A. R. (1971). Genetic clinic; a follow up. Lancet, 1, 281-285.

Cooke, J. R., and Raine, D. N. (1973). Competitive inhibition of renal tubular transport in the treatment of prolinaemia and hydroxyprolinaemia. In Treatment of Inborn Errors of Metabolism, edited by J. W. T. Seakins, R. A. Saunders, and C. Toothill, pp. 97-103. Churchill Livingstone, Edinburgh and London.

Council of Europe Public Health Committee (1973) Collective results of mass screening for inborn metabolic errors in eight European countries. Acta paediat. scand., 62, 413-416.

Cowie, V. (1973). Genetic and social aspects of prenatal and newborn population screening. Ann. clin. Biochem., 9, 112-114.

Department of Health and Social Security and Welsh Office (1971). Better Services for the Mentally Handicapped. Command 4683. HMSO, London.

Edwards, J. H. (1972). Genetic counselling. (Letter) Brit. med.J., 2, 22. Hubble, D. V. (1966). Congenital adrenal hyperplasia. In Basic Concepts of Inborn Errors and Defects of Steroid Biosynthesis, edited by K. S. Holt, and D. N. Raine, pp. 68-74. Livingstone, Edinburgh.

McKusick, V. A. (1971). Mendelian Inheritance in Man, 3rd ed. Johns Hopkins Press, Baltimore.

Medical Research Council Working Party on Phenylketonuria (1968). Present status of different mass screening procedures for phenylketonuria. Brit. med. J., 4, 7-13.

Office of Population Censuses and Surveys (1973). Registrar General's Statistical Review of England and Wales for the year 1971, Part 1. Tables, Medical. HMSO, London.

Raine, D. N. (1972). Management of inherited metabolic disease. Brit. med. J., 2, 329-336.

Raine, D. N. (1974). The Treatment of Inherited Metabolic Disease. M.T.P., Lancaster.

Raine, D. N., Cooke, J. R., Andrews, W. A., and Mahon, D. F. (1972). Screening for inherited metabolic disease by plasma chromatography (Scriver) in a large city. Brit. med. J., 3, 7-13.

Roberts, D. F. Chavez, J., and Court, S. D. M. (1970). The genetic component in child mortality. Arch. Dis. Childh., 45, 33-38.

Rothschild, Lord (1971). A Framework for Government Research and Development. (Including Lord Rothschild's Report) Command 4814. HMSO, London.

Scriver, C. R., Clow, C. L., and Lamm, P. (1973). On the screening, diagnosis and investigation of hereditary amino acidopathies. Clin. Biochem., 6, 142-188.

Westwood, A., and Raine, D. N. (1973). Some problems of heterozygote recognition in inherited metabolic disease with special reference to phenylketonuria In Treatment of Inborn Errors of Metabolism, edited by J. W. T. Seakins, R. A. Saunders, and C. Toothill, pp. 63-77. Churchill Livingstone, Edinburgh.

Westwood, A., and Raine, D. N. (1974). Heterozygote likelihood ratio (HLR) a new method of assigning carrier status for inherited metabolic diseases with special reference to the interpretation of the phenylalanine tolerance test in heterozygotes for phenylketonuria. In press.

World Health Organization (1972). Genetic Disorders: Prevention, Treatment and Rehabilitation. WHO Teco. Rep Ser. 497. 